\title{
Three-phase Inverter Development for Distributed Generation Purpose
}

\author{
Arthur C. Prates, José A. Pomílio, Hildo Guillard Jr., Joel F. Guerreiro, Fellipe S. Garcia
}

\begin{abstract}
The purpose of the project is the development of an open source three-phase inverter for distributed generation mainly for didactic use. The inverter supports many types of devices (Mosfets, IGBTs), with different possible functioning logics, without losing the layout comprehension.
\end{abstract}

\section{Key words: \\ Power electronics, CC-CA Converter, Layout}

\section{Introduction}

Systems of distributed energy, based in solar panels or battery banks, need a CC-CA converter for it's connection to the grid.

There are many regulations in Brazil $^{1}$ defining the waveform for one, two or three-phase converter while the discussion in the academy goes to the harmonic contamination $^{2}$ of the grid due these converters.

The current regulation aims mainly the power injection in the grid, but the companies responsible for the power distribution are yearly incorporating procedures for a better use of inverters in terms of reactive energy compensation, better voltage profile and soon harmonics compensation.

In this scenario is urgent the need of a device capable of those function in the universities in an open source version in order to study the effects and prepare professionals for these advances.

\section{Results and Discussion}

The concept of the project aims a 4 legs inverter- image 1- capable of $800 \mathrm{~V}$ and $200 \mathrm{kHz}$ switching frequency. In order to achieve it the project was divided in 5 main parts: Main Power Supply, Isolated Power supply, Protections/gate driver and Logic circuits.

The Main power supply was planned to have as input voltages between $14 \mathrm{~V}$ and $36 \mathrm{~V} \mathrm{CC}$ and delivers steady $8,5 \mathrm{~V} \mathrm{CC}$. The input voltage can be provided for any laptop's power supply.

The isolated power supply ensures $12 \mathrm{~V} / 5 \mathrm{~V}$ for the protection's and gate drive's circuit and it's replicated 8 times.

The core advance of the project dwells on the Mosfets protections, once the limits of voltage and frequency are higher than usual, aiming a versatile inverter.

The protections act over overheating and overcurrent of the power side and undervoltage of the driver in the logic side. The circuit is arranged in a way that one can recalculate the protections level according to the chosen switch. We've validated for the STW28N65M2 Mosfet..

The Logic circuit provide dead-time and enables the functionality of the inverter according to the protections status.

In the power side was detected the need of a snubber circuit $^{3}$ to allow the use for greater frequencies. Some empiric adjustments were requested, once the parallel arrange of the switches inserts noise due the interaction between the devices.
Along the year those parts were developed and carefully validated with new layouts, approaches and ideas.

The image 2 shows the turning on and off of the circuit using half phase with 100VDC-link and $78 \mathrm{kHz}$ switching frequency.

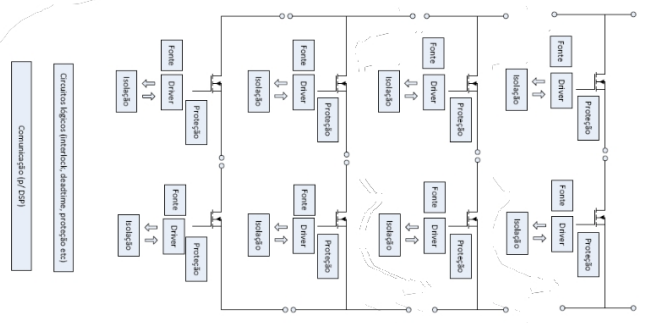

Image 1. Inverter's block diagram

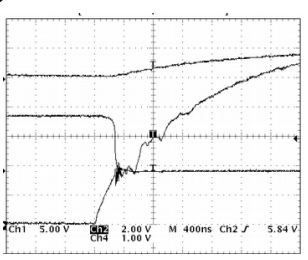

a) Turning on

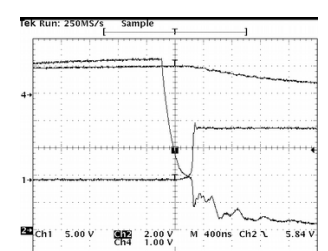

b) Turning OFF
Image 2. Operation of half phase with 100VDC and 78 $\mathrm{kHz}$ switching frequency.

\section{Conclusions}

The project presented itself as a challenge in many parts. Until the moment of this document release the efforts were towards the ease of the noise presented in the switching phase in order to allow the focus on the fine tuning of the protection and further built of the whole system.

As expected from a state of art project some barriers take a longer time to be pushed.

We believe that soon we will have a functioning Inverter ready to be used in the preparation of our students for future energy system's policies and to support new researches and advancements.

\section{Acknowledgement}

I would like to thank all the staff of the LCEE from which I've learned so much and the PIBIC program for this opportunity.

\footnotetext{
1 ANEEL, Resolução Normativa No 482, 2012.

${ }^{2}$ Pacific Gas and Electric Company, Electric Rule No. 21, Generating Facility Interconnections, Section H.2.i, 2015.

${ }^{3}$ Fundamentals of IGBT and MOSFETs gate driver circuits. TI Applications Note. L. Balogh
} 